\title{
Corporate venture capital: geração e acompanhamento de oportunidades de investimento em empresas inovadoras
}

\author{
Thiago Pinheiro Faury ${ }^{\mathrm{a}}$, Marly Monteiro de Carvalho ${ }^{\mathrm{b}}$ \\ a*thiagopfaury@hotmail.com, Schlumberger, Brasil \\ bmarlymc@usp.br, USP, Brasil
}

\begin{abstract}
Resumo
0 objetivo deste trabalho é compreender a utilização de estruturas corporate venture capital - CVC (capital de risco corporativo), identificando as motivações e as dificuldades no processo de implementação, com foco nos estágios de geração e acompanhamento de oportunidades de investimentos. A abordagem metodológica pautou-se inicialmente por uma revisão de literatura, seguida de um estudo de caso em uma empresa com unidade de novos negócios voltada ao CVC. Finalmente, foi utilizado um painel de especialistas da área de VC, composto por três grupos de especialistas: Mercado, Empreendedores e Neutro (acadêmicos, consultores em inovação e gerentes de incubadoras). Com o auxílio do software ATLAS.ti foi feita a análise de conteúdo dos discursos dos entrevistados, gerando um interessante painel a respeito das práticas de venture capital que poderá orientar não só a organização estudada, como também aos envolvidos na indústria de capital de risco, inovação e empreendedorismo. 0 trabalho aponta para a busca de opções de investimentos alinhadas aos mercados alvo, mas também de empreendedores alinhados à filosofia da organização. Também se observou diferenças na percepção entre os atores do painel de especialistas. Finalmente, foi destacada a importância de intermediários na aproximação das empresas inovadoras e o CVC.
\end{abstract}

Palavras-chave

Capital de risco. Capital de risco corporativo. Inovação. Empreendedorismo.

\section{Introdução}

$\mathrm{O} V \mathrm{C}$ se originou no mercado financeiro e atua diretamente no desenvolvimento de empresas. A valorização da companhia e a possível venda de ações determinarão se o investidor terá ou não lucros (CRIATEC, 2009).

0 crescimento do mercado de VC independente provocou interesse em empresas inovadoras, que procuraram montar seus programas de capital de risco corporativo (corporate venture capital - CVC).

Ao longo do tempo, as estruturas CVCs têm evoluído. Várias empresas inovadoras como Adobe, Intel e lucent introduziram programas de CVC para promover uma maior inovação e motivar funcionários a se tornarem mais empreendedores e a correrem mais riscos. No entanto, esse processo que não é recente teve vários altos e baixos (CHESBROUGH, 2000).
Até o início da década de 1970,25\% das empresas listadas na Fortune 500 tinham programa CVC, mas grande parte se desfez deles. Foi somente na década seguinte, quando o mercado de VC independente voltou a crescer, que as empresas renovaram o seu interesse no CVC. Novamente, houve desaceleração do mercado em 1987 e ressurgimento na década seguinte. Segundo Chesbrough (2000), as tentativas de CVC têm encontrado sucesso apenas temporário, pois enfrentam várias dificuldades e terminam com a eventual interrupção da iniciativa.

Embora as estruturas de VC independente sejam um ponto de referência para analisar as estruturas de CVC, existem muitas diferenças entre elas. 0 objetivo deste trabalho é compreender a utilização de estruturas CVCs, com ênfase em duas fases específicas do processo de VC: a geração de oportunidades e 0 
acompanhamento (pós-investimento) das empresas apoiadas pelo fundo. Pretende-se ainda identificar as motivações e as dificuldades no processo de implementação, na perspectiva de diferentes atores desse processo

A abordagem metodológica pautou-se inicialmente em uma revisão de literatura, com elaboração de estrutura teórico-conceitual. Em seguida realizou-se painel de especialistas da área de VC, que utilizou questionários voltados a três grupos de especialistas: Mercado, Empreendedores e Neutro (acadêmicos, consultores em inovação e gerentes de incubadoras). Finalmente, foi realizada uma análise de uma organização que está implementando uma unidade de novos negócios voltada ao CVC, em que se busca compreender as motivações, dificuldades e o processo de CVC adotado. Os resultados das três etapas são discutidos ao longo do processo.

Este artigo está estruturado em 5 seções. A próxima seção apresenta a síntese do quadro teórico. Em seguida, apresenta-se a abordagem metodológica utilizada na pesquisa. As seções 4 e 5 apresentam os resultados obtidos e as conclusões e limitações do estudo.

\section{Venture capital e inovação: síntese da literatura}

\subsection{Venture capital $(V C)$}

$\mathrm{O} \mathrm{VC}$ se originou no mercado financeiro e atua diretamente no desenvolvimento de empresas. Quando é feito o investimento, o empreendedor cede uma parte das ações da empresa ao investidor. A valorização da companhia, e a possível venda de ações, determinará se o investidor terá ou não lucros. $0 \mathrm{VC}$ difere de um financiamento comum, pois o empreendedor está livre de qualquer dívida caso a valorização não ocorra conforme esperado. Além disso, não são exigidos avalistas ou garantias (CRIATEC, 2009).

As expressões private equity e venture capital podem ser traduzidas para o português como "capital empreendedor" ou "capital de risco". No entanto, face à prática de mercado, este trabalho irá manter a expressão original, em inglês, normalmente abreviada pelas siglas PE e VC (LATIN..., 2008).

Segundo Zider (1998), a indústria de VC tem quatro atores principais. Os empreendedores, que necessitam de investimentos. Os investidores, que desejam obter altos retornos. Os bancos de investimento, que precisam de empresas para vender. Finalmente, os capitalistas de risco, que ganham dinheiro criando um mercado para os três atores precedentes.

0 investidor pode ser individual (angel investor), corporativo ou institucional (geralmente fundos de investimento). Cabe distinguir que quando o investidor é uma empresa de maior porte investindo na aquisição de participação em empresas menores o capital recebe a classificação capital de risco corporativo (corporate venture capital - $\mathrm{CVC}$ ), sendo a operação chamada de external corporate venturing, categoria na qual se encaixam os investimentos da organização estudada neste trabalho (GARCEZ; ANSELMO, 2005).

Além do dinheiro investido, os fundos de VC auxiliam os empreendedores na profissionalização da gestão do negócio, contribuindo, por exemplo, com experiência profissional e expansão da rede de contatos. Esse auxílio muitas vezes pode ser até mais importante do que o próprio montante investido, sendo fundamental tanto para o sucesso do empreendedor quanto para a lucratividade dos fundos de investimento (CRIATEC, 2009).

É interessante notar que o empreendedor, além de desejar ter um parceiro que o guie em suas decisões gerenciais, vê o VC como uma das poucas saídas financeiras para alavancar sua empresa. 0 nicho de VC existe por causa da estrutura e das regras do mercado de capitais. Alguém que tenha uma ideia ou uma nova tecnologia geralmente não tem nenhuma outra instituição a quem recorrer. $0 \mathrm{VC}$ preenche um vazio que existe entre fontes de financiamento para a inovação (grandes corporações/governos e familiares/ amigos do empreendedor) e fontes tradicionais e baratas de capital disponíveis para projetos em curso (ZIDER, 1998).

Apesar disso, os investimentos de VC são invariavelmente feitos em empresas com grande potencial de crescimento. A elevada possibilidade de retorno e taxa de crescimento são condições necessárias para justificar os custos elevados envolvidos na estruturação, negociação e monitoramento do investimento, bem como a baixa liquidez e o risco associados ao investimento em empresas fechadas ou de baixa capitalização (CARVALHO; RIBEIRO; FURTADO, 2006). De acordo com Zider (1998, p. 133), é um mito considerar que capitalistas de risco investem em boas pessoas e boas idéias. A realidade é que eles investem em boas indústrias, isto é, indústrias que sejam mais competitivas do que o mercado como um todo

Tyebjee e Bruno (1984) indicam três grandes fontes de geração: os mapeamentos tecnológicos, os contatos frios (por exemplo, telefonemas de desconhecidos) e as indicações. Os autores representam as fases do processo de VC conforme a Figura 1.

No que concerne às atividades posteriores ao investimento, Steier e Greenwood (1995) enfatizam que poucos autores as têm abordado.

Os investimentos de VC são normalmente feitos sob a forma de tranches, isto é, parcelas que são liberadas à medida que a empresa apoiada pelo 
fundo atinge certas metas pré-determinadas no momento da liberação da $1^{a}$ tranche. Evidentemente, as negociações para liberação de tranches posteriores à primeira são relativamente árduas, segundo Tyebjee e Bruno (1984).

Chesbrough (2000), a partir da análise do programa da Exxon de capital de risco, faz uma análise comparativa das estruturas de VC e CVC segundo quatro atributos, conforme ilustra o Quadro 1.

Como pode ser observado no Quadro 1, existem várias diferenças estruturais entre o CVC e o VC que justificam um estudo distinto dessas duas estruturas, de forma a entender suas vantagens e desvantagens, as quais podem auxiliar na redução das expressivas taxas de descontinuidade dos programas de CVC.

\subsection{Inovação e incentivo}

Segundo Levy (2009), no âmbito das políticas de incentivo à inovação promovidas pelo governo brasileiro, destacam-se a Lei de Inovação (n. 10.973, de 2/12/2004) e a Lei do Bem (n. 11.196 - capítulo III, de 21/11/2005). Apesar da Lei de Inovação contribuir para a articulação dos órgãos envolvidos com a inovação no Brasil, é a Lei do Bem que realmente desperta um interesse de as empresas investirem em inovação, pois oferece incentivos fiscais para apoiar as atividades empresariais de pesquisa, desenvolvimento e inovação tecnológica. Nesse sentido, o Quadro 2 destaca algumas das principais linhas de apoio para investimentos em inovação.

Pela análise do Quadro 2, percebemos, portanto, como o venture capital se insere no contexto da inovação. Essa relação, aliás, explica em parte a erosão do modelo de inovação fechada e o surgimento da era da inovação aberta, como sugerido por Chesbrough (2003), em que a inovação se dá com colaboração (LOPES; CARVALHO, 2012).

Chesbrough (2003) explica que durante a maior parte do século XX a lógica que imperava nas grandes

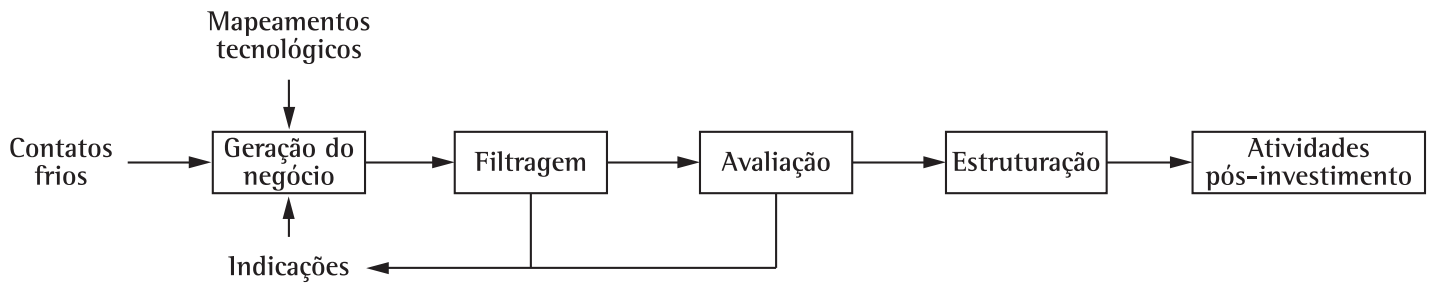

Figura 1. Fases do processo de VC (TYEBJEE; BRUNO, 1984).

Quadro 1. Comparação das estruturas de VC e CVC (adaptado de Chesbrough, 2000).

\begin{tabular}{|l|l|l|}
\hline \multicolumn{2}{|c|}{ Atributo } & \multicolumn{1}{c|}{ CVC } \\
\hline Intensidade de incentivo & Mais fraco & Forte \\
\hline Disciplina financeira & Mais fraco & Forte \\
\hline Monitoramento & Interno & Externo, incluindo fora do board \\
\hline Descobrindo alternativas de novos modelos de negócios & Restrito & Irrestrito \\
\hline Horizonte de tempo & Indefinido & Ligado ao tamanho do fundo \\
\hline Escala do capital investido & Potencialmente grande & Menor \\
\hline Coordenação de complementaridades & Extensivo & Limitado \\
\hline Retenção do grupo de aprendizagem & Forte & Mais fraco \\
\hline
\end{tabular}

Quadro 2. Principais linhas de apoio para investimentos em inovação (NAKAGAWA, 2009; LEVY, 2009).

\begin{tabular}{|l|l|}
\hline \multicolumn{1}{|c|}{ Linha de apoio } & \multicolumn{1}{c|}{ Exemplos de fontes de recursos } \\
\hline Incentivos fiscais & - Benefícios da lei do Bem \\
\hline Geração interna (bootstrap) & $\begin{array}{l}\text { - Antecipação de recebimentos e postergação de pagamentos } \\
\text { - Venda de franquias/Venda de royalties }\end{array}$ \\
\hline Dívida & $\begin{array}{l}\text { - Bancos (linhas de crédito, leasing etc.) } \\
\text { - Financiamento de importação/exportação }\end{array}$ \\
\hline Subvenção (grant ou "dinheiro a fundo perdido") & $\begin{array}{l}\text { - Agências de fomento à pesquisa (FAPESP, FAPEMIG etc.) } \\
\text { - Concursos de planos de negócios }\end{array}$ \\
\hline Ações (funding) & $\begin{array}{l}\text { - Fundadores (veículos, apartamentos, família etc.) } \\
\text { - Angels (investidores individuais) }\end{array}$ \\
\hline
\end{tabular}


empresas era a da inovação fechada. Nesse sistema, a empresa gera, desenvolve e comercializa suas próprias ideias. Essa filosofia de autoconfiança dominou as operações de P\&D de muitas corporações durante o século XX.

No entanto, no final do século $X X$, o grande crescimento da indústria de $\mathrm{VC}$ permitiu às pessoas que não conseguiam aprovar suas ideias de novos negócios dentro das grandes corporações deixassem seu emprego e criassem novas empresas com o apoio dos investimentos de VC.

Dessa forma surge o modelo de inovação aberta. Nesse novo ambiente de inovação, nem sempre a organização que investiu na inovação lucra com o investimento, portanto a proteção de sua propriedade intelectual não é condição suficiente, embora necessária. Deve-se também perscrutar as inovações de outros e utilizá-las através de licenciamento, empreendimentos mistos e outros arranjos que sejam lucrativos para ambos. É importante ressaltar que o foco das inovações não deve ser apenas o mercado atual, mas a busca de novos mercados. (CHESBROUGH, 2003; CHESBROUGH; CROWTHER, 2006; CARVALHO, 2009).

Destaca-se que uma empresa não precisa restringir-se a um determinado tipo de operação no processo de inovação aberta. Chesbrough (2003) indica que embora tanto o modelo de inovação aberta quanto o de fechada consigam eliminar bem os projetos chamados falsos positivos (isto é, ideias ruins que pareciam inicialmente boas), a inovação aberta incorpora a capacidade de "salvar os falsos negativos" (projetos que inicialmente pareciam não ter futuro e que depois se mostram promissores). Isso porque o modelo de inovação aberta evita jogar fora ideias, tentando capitalizá-las por diversos meios, como licenças, empreendimentos mistos e aquisições/ desinvestimentos (JONG et al., 2007).

Nesse sentido, há grande aderência entre o conceito inovação aberta e o CVC. A etapa de inovação que está mais próxima dessa conexão entre inovação aberta e 0 CVC é o fuzzy front end (FFE), termo popularizado por Smith e Reinertsen (1992) na designação da fase mais difusa do processo de inovação, que compreende a fase de geração de ideias. Contudo, não há um consenso na literatura sobre sua definição (ver Figura 2). Para Cooper, Edgett e Kleinschmidt (2002), o FFE é como um mecanismo de geração de ideias, dentro de um processo de desenvolvimento de produtos Stage Gate ${ }^{\circledR}$. Já Khurana e Rosenthal (1998) e Kim e Wilemon (2002) vêem o FFE como um processo, no qual se incluem as etapas de formulação e comunicação da estratégia do produto, avaliação e identificação de oportunidades, geração de ideias, definição do produto, planejamento do projeto e revisões iniciais. Há também forte ligação com mecanismos de alinhamento estratégico

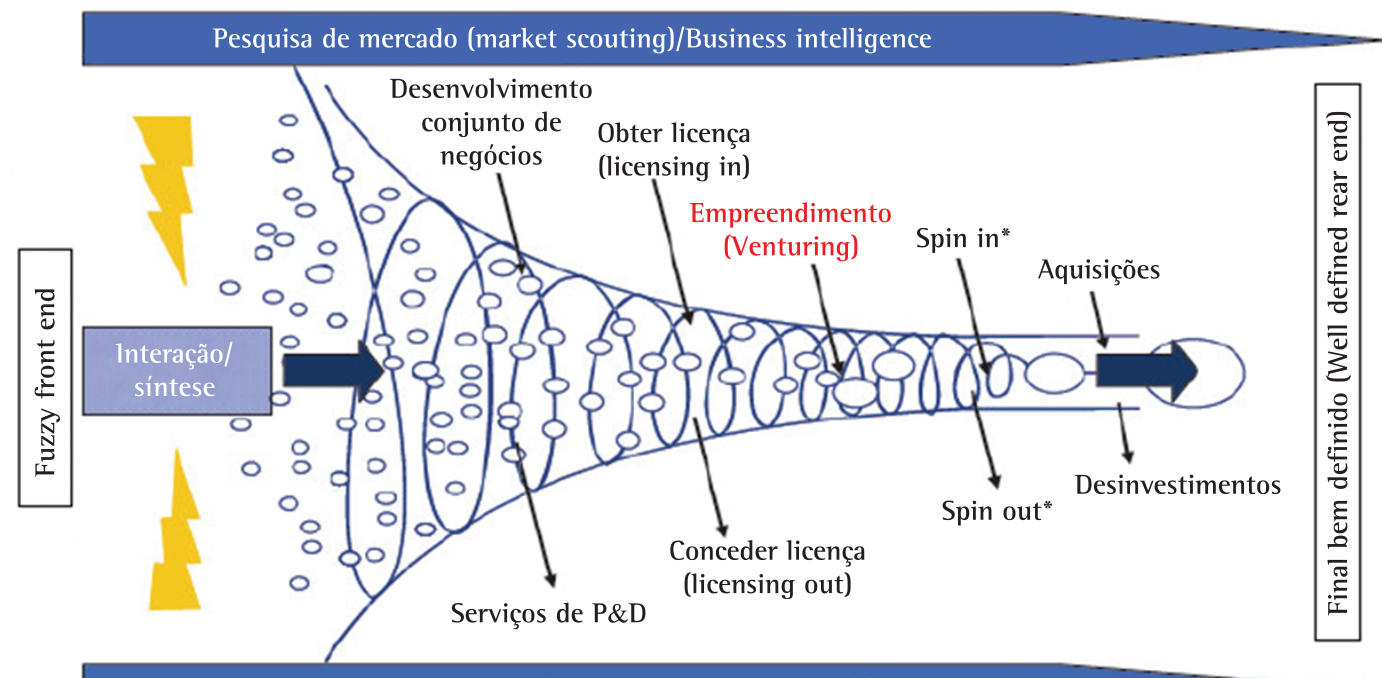

Desenvolvimento de competências (Competence development)/Technology intelligence

Gestão de ativos intelectuais (Intellectual asset management)

"Spin-in: “Co-locação" de uma empresa para explorar expertise e instalações acadêmicas

*Spin-out: Criação de uma empresa para comercializar propriedade intelectual acadêmica

Figura 2. Criação de valor através da inovação aberta (JONG et al., 2007). 
(PRIETO; CARVALHO; FISCHMANN, 2009; PRIETO; CARVALHO, 2011) e gestão de portfólio (CASTRO; CARVALHO, 2010).

\subsection{Quadro síntese}

À primeira vista, os temas aqui abordados sugerem uma desconexão, pois são tratados a partir de diferentes escolas com lastro nas áreas de finanças, administração, $P \& D$ e marketing, entre outras.

No entanto, no contexto de análise do CVC eles têm forte conexão, partindo-se da perspectiva da empresa. Percebe-se que impera atualmente uma visão de que negócios inovadores trazem consigo grande rentabilidade. Daí o interesse das grandes corporações de investir em portfólios de empreendimentos inovadores - que muitas vezes começam do zero e precisam de aportes de capital providos, em grande parte, por capital de risco.

A fim de compreender a estrutura do CVC sob os vários aspectos levantados na revisão da literatura, foi criado o quadro síntese mostrado no Quadro 3.

\section{Método}

Dado o objetivo, apresentado na seção introdutória, de compreender a utilização de estruturas CVC, com ênfase em duas fases específicas do processo de VC - a geração e o acompanhamento, optou-se por uma pesquisa de caráter exploratório, estruturada em três etapas.

A primeira etapa da pesquisa bibliográfica foi realizada com busca de artigos acadêmicos em bases de dados como ISI Web of Knowledge, a partir do portal de periódicos da CAPES, totalizando 17 artigos de 13 periódicos. A partir da análise desse grupo inicial de literatura, foram localizadas novas referências de interesse, que resultaram no quadro síntese da literatura. Os principais resultados dessa etapa foram apresentados na seção 2, cujo quadro síntese pautou a elaboração do instrumento utilizado na pesquisa de campo.
Os temas levantados na literatura (ver Quadro 3) foram debatidos através de um painel de especialistas, de modo a compreender a pluralidade de visões dos diferentes atores na indústria de VC.

Durante a montagem dos grupos de especialistas, a preocupação foi segmentar tais grupos de acordo com suas experiências profissionais. 0 ponto de partida foram os atores propostos por Zider (1998): empreendedores, capitalistas de risco, investidores e bancos de investimento. Como o perfil dos capitalistas de risco, dos investidores e dos bancos de investimento muitas vezes se confundem, todos foram incluídos num grupo denominado Mercado. 0 segundo grupo formado foi o dos Empreendedores.

Já antecipando as questões que seriam direcionadas a esses dois grupos, percebeu-se que determinadas respostas obtidas seriam enviesadas pelo fato de cada profissional focar o mercado em que atua e possivelmente não olhar o contexto do venture capital, empreendedorismo e inovação como um todo. Assim sendo, decidiu-se criar um terceiro grupo Neutro formado por acadêmicos, consultores em inovação e gerentes de incubadoras.

Com isso, o painel de especialistas foi composto por 5 profissionais do grupo Mercado, 7 do grupo Empreendedores e 7 do grupo Neutro. Como cada um dos grupos teve a colaboração de menos de 10 indivíduos, não faria sentido realizar uma análise estatística das informações por eles fornecidas. Logo, a fim de organizar tais informações, foi escolhida a metodologia de análise de conteúdo. Segundo Neuendorf (2002, p. 10), a análise de conteúdo busca ao mesmo tempo trazer aspectos quantitativos e resumidos de mensagens através de métodos científicos e não se limita aos tipos de variável que podem ser medidos ou aos contextos nos quais as mensagens são criadas ou apresentadas.

Para facilitar o tratamento das mensagens que foram passadas pelos entrevistados durante a execução da fase painel de especialistas utilizou-se o software ATLAS.ti, popular em trabalhos acadêmicos que utilizam análise de conteúdo (MORA JUNIOR, 2009).

Quadro 3. Quadro síntese da revisão de literatura.

\begin{tabular}{|l|l|}
\hline \multicolumn{1}{|c|}{ Conceitos } & \multicolumn{1}{c|}{ Fontes } \\
\hline Venture capital; definição, atores e fases do processo & $\begin{array}{l}\text { Elango et al. (1995), Zider (1998), Carvalho, Ribeiro e Furtado (2006), Chen } \\
\text { (2009), CRIATEC (2009), Nakagawa (2009), Garcez e Anselmo (2005) e Steier e } \\
\text { Greenwood (1995) }\end{array}$ \\
\hline Geração e acompanhamento & Tyebjee e Bruno (1984) e Steier e Greenwood (1995) \\
\hline Distinções entre CVC e VC & Chesbrough (2000) \\
\hline lnovação fechada e inovação aberta & Chesbrough (2003) e Levy (2009) \\
\hline Fuzzy front end & $\begin{array}{l}\text { Smith e Reinertsen (1992), Koen et al. (2002), Cooper, Edgett e Kleinschmidt } \\
\text { (2002) e Kim e Wilemon (2002) }\end{array}$ \\
\hline
\end{tabular}


A vantagem do software ATLAS.ti é a sua praticidade para se analisar discursos. Digitando cada entrevista feita com um especialista não há necessidade de se sintetizar informações - o software permite que trechos de determinadas entrevistas sejam enquadrados em códigos definidos pelo próprio usuário. Além disso, o software também permite realizar buscas booleanas por famílias de códigos. Isso facilitou bastante a montagem dos quadros apresentadas na próxima seção. A Figura 3 ilustra a aplicação do software ATLAS.ti na análise da entrevista com um dos membros do grupo Neutro.

Algumas das questões apresentadas aos especialistas trabalhavam com escalas numéricas ou escalas de Likert que foram convertidas em escalas numéricas. 0 tratamento desses dados foi feito com o auxílio dos softwares Minitab (gráficos boxplot e dotplot) e Microsoft Excel (determinação de média, mediana e moda).

Concomitantemente, foi realizada uma pesquisa exploratória, com características de pesquisa-ação, tais como a estreita associação com uma ação, e o envolvimento cooperativo de pesquisadores e participantes da organização estudada (THIOLLENT, 2004). A empresa selecionada apresenta um programa de CVC e dispôs-se a colaborar na pesquisa. A organização estudada (doravante denominada organização) é uma empresa dedicada a prover soluções de infraestrutura para setores-chave da economia como energia elétrica, óleo e gás, indústrias de processamento, mineração, metalurgia, telecomunicações e tecnologia da informação (FUNDAÇÃO..., 2007). Para auxiliá-la na tarefa de elaboração de um programa de CVC, a área de novos negócios da organização estabeleceu um contrato de 6 meses (janeiro a junho de 2009) com uma instituição parceira (IP), empresa que atua na prestação de serviços de gestão da inovação, na gestão de capital empreendedor, no uso de incentivos fiscais e captação de recursos para inovação. A pesquisa foi desenvolvida no período de 2008 e 2009, contando com várias fontes de evidência tais como entrevistas, observação direta, análise de documentos da organização e da instituição parceira. A Figura 4 sintetiza as etapas da pesquisa.

\section{Resultados}

Nesta seção são apresentados os resultados deste trabalho, destacando-se a síntese dos resultados do painel de especialistas, o diagnóstico da área de venture capital da organização estudada e a proposição do framework para a geração e o acompanhamento.

\subsection{Painel de especialistas}

Nessa seção é feita a síntese dos resultados do painel de especialistas segundo os grupos pesquisados.

\subsubsection{Grupo Neutro: acadêmicos, consultores e gerentes de incubadoras}

É interessante começar o diagnóstico do painel de especialistas pelo grupo Neutro por este ter apresentado

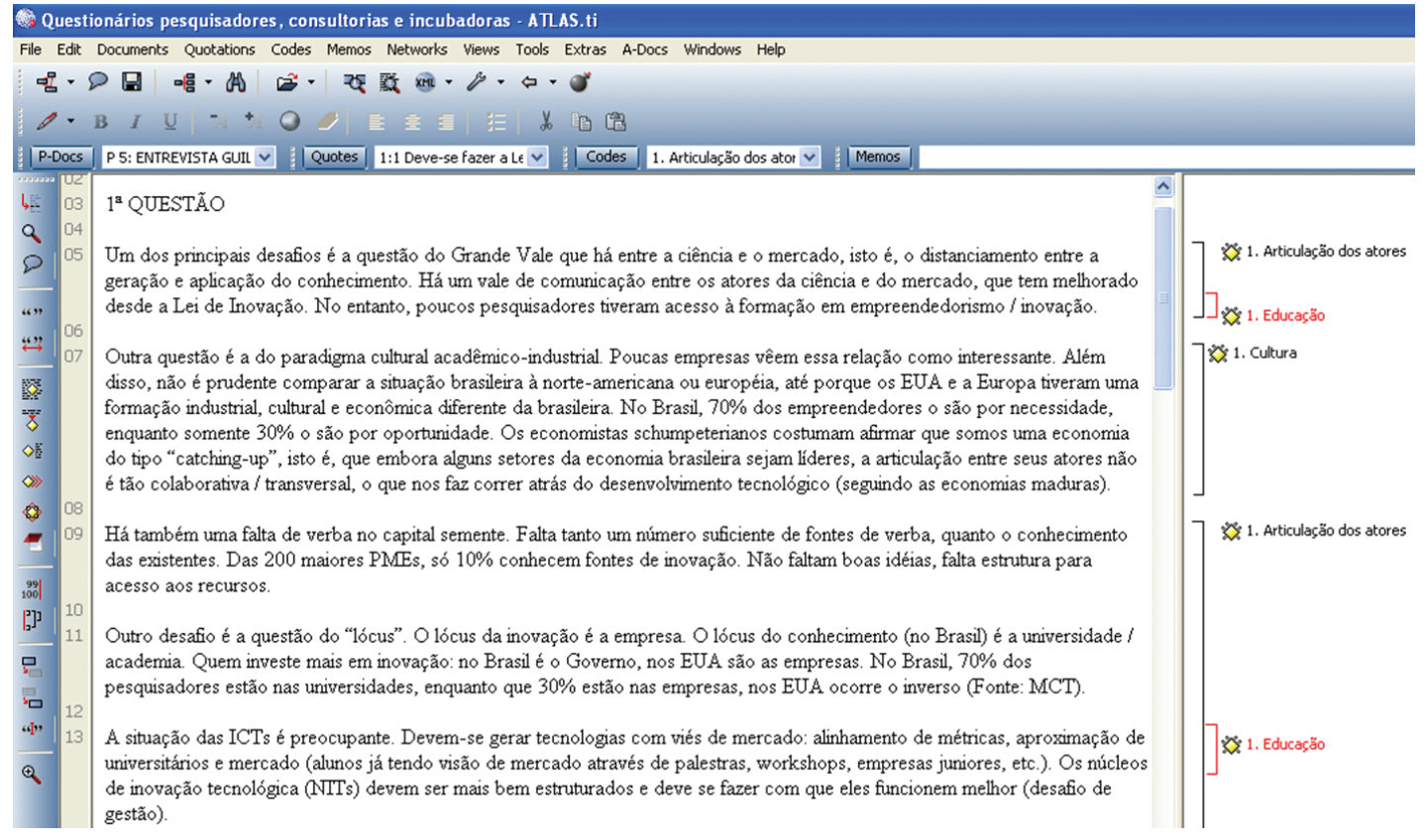

Figura 3. Aplicação do software ATLAS.ti à análise de uma entrevista. 


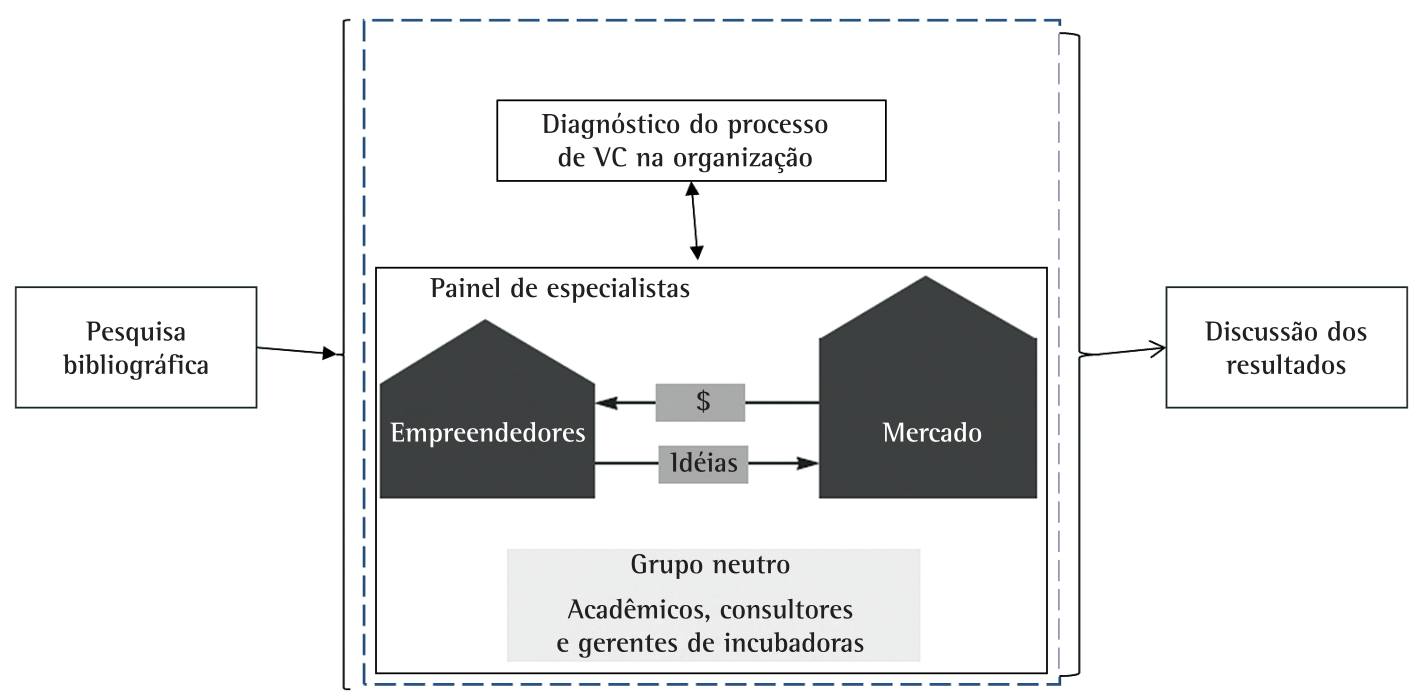

Figura 4. Etapas da pesquisa.

o maior número de colaboradores e pelo fato de o questionário a eles dirigido possuir perguntas mais abrangentes, trazendo um rico repertório para a análise de conteúdo.

0 perfil dos componentes do grupo Neutro é o seguinte:

- Acadêmicos: 1 ex-professora da FGV-SP e autora de um livro na área de capital de risco e 1 professor da Fundação Vanzolini com atuação junto ao SEBRAE-SP;

- Consultores em inovação: 1 consultor de São Paulo e professor do curso em Inovação e Empreendedorismo do PECE-USP e 2 consultores de Campinas que responderam ao questionário conjuntamente;

- Gerentes de incubadoras': 1 gerente do CIETEC (USP), 2 gerentes da INCAMP (UNICAMP), que responderam conjuntamente, e 1 presidente da ANPROTEC (Associação Nacional de Entidades Promotoras de Empreendimentos Inovadores).

Algumas perguntas voltadas ao grupo Neutro tinham por objetivo verificar quais seriam as tendências em inovação, capital de risco e empreendedorismo no Brasil nos próximos 3 a 5 anos. Esse período de 3 a 5 anos foi colocado pensando-se no horizonte de planejamento que os investidores de venture capital utilizam para avaliar oportunidades de investimento.

Os especialistas parecem concordar que para se fomentar a inovação no Brasil é preciso articular de maneira convergente os atores dessa indústria

\footnotetext{
'Muito embora a ANPROTEC não seja uma incubadora, ela é a "associação que representa os interesses das incubadoras de empresas, parques tecnológicos e empreendimentos inovadores no Brasil". Fonte: ANPROTEC <http://www. anprotec.org.br/publicacaoconheca.php?idpublicacao=1>. Acesso em: 11 out. 2009.
}

e realizar uma série de reformas em campos como Educação, Cultura, Legislação Tributária e Trabalhista. A Tabela 1 resume os pontos mais emblemáticos na visão do grupo Neutro.

Com relação aos principais focos de investimento nos próximos 3 a 5 anos, as respostas dos especialistas convergiram em setores de cunho tecnológico, como Energias Limpas, Tecnologias da Informação e Comunicação (TIC), Biotecnologia e Nanotecnologia.

Alguns setores foram citados com base em perspectivas nacionais de curto prazo, como o de Construção Civil (por conta do Programa de Aceleração do Crescimento - PAC) e o de Petróleo e Gás Natural (devido à descoberta da camada pré-sal).

Um dos especialistas considerou como foco a tendência de convergência tecnológica, isto é, a construção de soluções tecnológicas a partir de dois ou mais setores da economia, como é o caso da genômica, que incorpora conceitos dos campos da biotecnologia e da informática.

É interessante notar que a maior parte dos setores citados coincide com os setores estratégicos definidos pelo Ministério de Ciência e Tecnologia (MCT) em seu Plano de Ação 2007-2010 para a Ciência, Tecnologia e Inovação. A exceção fica por conta dos setores que interessam mais ao governo do que às empresas em geral, como Amazônia e Semiárido, Programa Espacial, Programa Nuclear, Defesa Nacional e Segurança Pública.

Em uma pergunta dirigida ao grupo Neutro, a intenção inicial era captar os motivos pelos quais as pequenas e médias empresas (PMEs) procuram o auxílio de incubadoras, bem como aqueles que 
Tabela 1. Principais desafios para se gerar inovação no Brasil.

\begin{tabular}{|c|c|c|c|c|c|c|c|c|c|}
\hline \multirow{3}{*}{ Dimensão } & \multirow{3}{*}{ Desafio } & \multicolumn{7}{|c|}{ Desafio apontado por } & \multirow{3}{*}{ Citações } \\
\hline & & \multicolumn{2}{|c|}{ Acad. } & \multicolumn{2}{|c|}{ Cons. } & \multicolumn{3}{|c|}{ Ger. incub. } & \\
\hline & & A1 & $\mathrm{A} 2$ & C1 & $\mathrm{C} 2$ & G1 & G2 & G3 & \\
\hline \multirow{5}{*}{$\begin{array}{l}\text { Articulação dos } \\
\text { atores }\end{array}$} & Empreendedores fortemente dependentes das universidades & $\mathrm{x}$ & & & & $\mathrm{x}$ & & & 2 \\
\hline & $\begin{array}{l}\text { Mecanismos desarticulados: os empreendedores ficam perdidos em } \\
\text { meio a tantas opções }\end{array}$ & & & & $\mathrm{x}$ & & & $\mathrm{x}$ & 2 \\
\hline & Há conflitos na adoção das lógicas de market pull e technology push & & & & $x$ & & & $x$ & 2 \\
\hline & $\begin{array}{l}\text { Os núcleos de inovação tecnológica (NITs) ainda estão se } \\
\text { estruturando e o papel deles ainda é incipiente }\end{array}$ & & & & $\mathrm{x}$ & $\mathrm{x}$ & & & 2 \\
\hline & $\begin{array}{l}\text { As empresas não estão acostumadas a lidar com as universidades } \\
\text { (e vice-versa) }\end{array}$ & & & $x$ & & $x$ & $x$ & & 3 \\
\hline $\begin{array}{l}\text { Compreensão da } \\
\text { inovação }\end{array}$ & $\begin{array}{l}0 \text { tecido empresarial em geral não entende o que é inovação } \\
\text { (obs.: há exceções) }\end{array}$ & & $x$ & & & & & $x$ & 2 \\
\hline Cultura & $\begin{array}{l}\text { Falta viés comercial nas universidades: paradigma que começa a ser } \\
\text { quebrado }\end{array}$ & & $x$ & & & $x$ & & & 2 \\
\hline $\begin{array}{l}\text { Indústria de } \\
\text { venture capital }\end{array}$ & $\begin{array}{l}\text { Deve-se criar uma indústria sólida de venture capital, isso geraria } \\
\text { uma constância no investimento em novas empresas }\end{array}$ & & $x$ & $X$ & $x$ & & & & 3 \\
\hline Políticas públicas & Desburocratizar a criação e operação de novas empresas & & & $\mathrm{x}$ & $\mathrm{x}$ & $\mathrm{x}$ & & & 3 \\
\hline
\end{tabular}

Quadro 4. Principais motivos pelos quais PMEs e grandes empresas procuram incubadoras e consultorias.

\begin{tabular}{|c|c|c|}
\hline & Incubadoras & Consultorias \\
\hline PMEs & $\begin{array}{l}\text { - Infraestrutura disponível (espaço físico do escritório, acesso a laboratórios/pesquisadores) } \\
\text { - Poder de marca (a incubada poder dizer que está no endereço de uma instituição } \\
\text { conceituada) } \\
\text { - Ambiente protegido com custo reduzido: menor probabilidade de quebra da empresa } \\
\text { dentro da incubadora do que fora } \\
\text { - Networking: ambiente que promove a cooperação entre incubadas e amplia a rede de } \\
\text { contatos dos empreendedores } \\
\text { - Apoio na gestão do negócio (mentoring) }\end{array}$ & $\begin{array}{l}\text { - PRIME (da FINEP): } \\
\text { obrigatoriedade de se gastar } \\
\text { com consultorias de gestão/ } \\
\text { mercado } \\
\text { - Apoio na captação de } \\
\text { recursos (fomento, capital de } \\
\text { risco etc.) }\end{array}$ \\
\hline $\begin{array}{l}\text { Grandes } \\
\text { empresas }\end{array}$ & $\begin{array}{l}\text { - Alinhamento de algumas empresas à abordagem da inovação aberta (tendência que vem } \\
\text { ganhando força nos últimos 4-5 anos) } \\
\text { - Fontes de inovação (novos produtos): é mais barato buscar nas incubadoras do que gastar } \\
\text { com P\&D internamente } \\
\text { - Interesse em criar um braço tecnológico (parcerias estratégicas) }\end{array}$ & $\begin{array}{l}\text { - Busca de experts que já } \\
\text { têm know-how na área de } \\
\text { inovação } \\
\text { - Inserção nas políticas } \\
\text { públicas de inovação } \\
\text { - Utilização da Lei do Bem }\end{array}$ \\
\hline
\end{tabular}

levam as grandes empresas a buscarem consultorias em inovação. Buscava-se entender quais são os intermediários entre as empresas inovadoras e o CVC das grandes empresas, compreendendo o papel desses intermediários (como as incubadoras, as empresas de consultoria). 0 que surpreendeu foi o fato de vários especialistas apontarem também as ligações menos evidentes, ou seja, entre PMEs e consultorias e entre grandes empresas e incubadoras (ver Quadro 4).

Diversos autores ressaltam a importância do venture capital para alavancar empreendimentos inovadores. 0 que poucos colocam é quão importante é o papel do VC diante de outras linhas de apoio para investimentos em inovação. Com isso em mente, foi pedido aos membros do grupo Neutro que avaliassem a importância relativa das cinco linhas de apoio: incentivos fiscais, geração interna, dívida, subvenção e ações.
Uma observação que foi feita logo pelos primeiros entrevistados foi a de que a importância relativa entre as linhas de apoio varia de acordo com o momento em que a empresa se encontra em seu ciclo de vida, o que foi corroborado por estudos de Pavani (2003). Assim, a pergunta inicial foi reformulada de forma a levar em consideração a situação de empresas nascentes e estabelecidas. Para cada tipo de empresa (nascente ou estabelecida), cada especialista deveria colocar em ordem de importância as cinco linhas de apoio, numerando-as de 5 a 1 , sendo 5 a mais importante e 1 a menos importante.

A fim de mostrar as discrepâncias de percepção entre os respondentes e o efeito da fase em que as empresas se encontram no seu ciclo de vida, foram criados gráficos estratificados, sendo um deles mostrado na Figura 5. Não foi possível detectar diferenças nítidas entre os estratos, pois em todos 


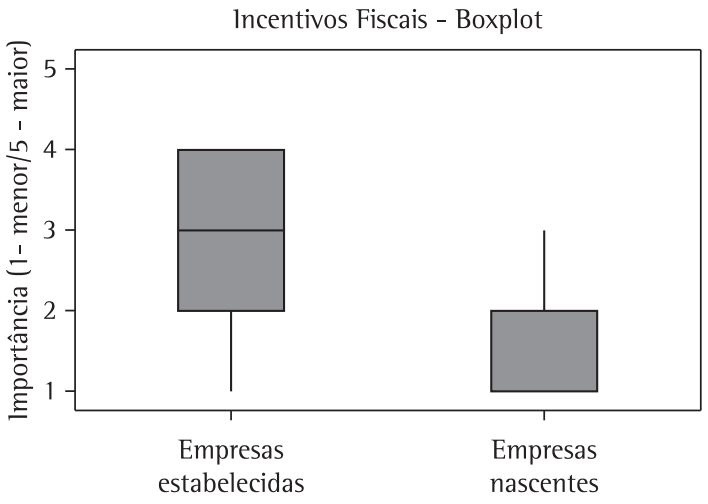

Fase

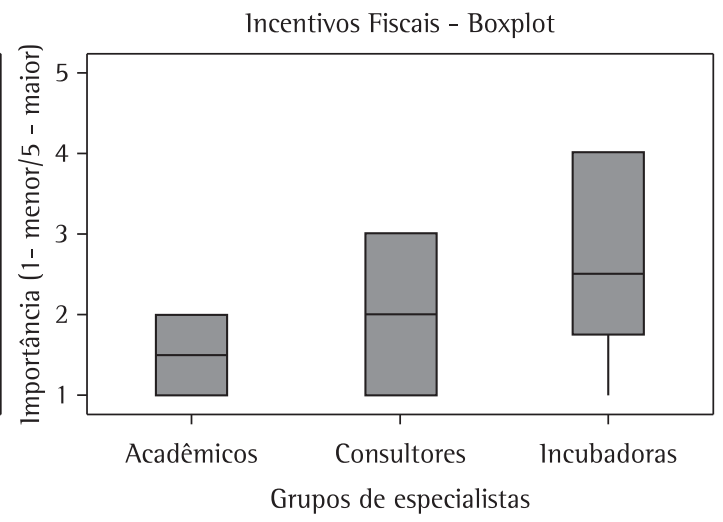

Figura 5. Importância estratificada dos incentivos fiscais. Nota: Elaborada no software Minitab.

os casos há intersecção dos intervalos de valores de importância. No entanto, a dispersão dos valores ao longo dos quartis permite fazer algumas inferências:

- A subvenção é percebida por todos os estratos de especialistas como uma das primeiras opções buscadas tanto pelas empresas nascentes quanto pelas estabelecidas;

- De modo geral, a percepção é de que ações são mais utilizadas por empresas nascentes, enquanto que incentivos fiscais e geração interna são mais utilizados por empresas estabelecidas;

- Algumas categorias de respondentes divergem das demais em determinadas linhas de apoio, como os consultores, que valorizam mais a dívida, e os acadêmicos, que valorizam mais as ações.

0 que caracteriza um empreendimento como interessante para uma incubadora ou uma consultoria em inovação? Foi esta uma das perguntas dirigidas ao grupo Neutro. Seu objetivo era captar elementos que pudessem ajudar a compreender por que tantos empreendimentos não passam pelo crivo de incubadoras e consultorias em inovação, os quais, consequentemente, teriam muitas dificuldades para passar pelo crivo de investidores.

Dentre as dimensões de fatores de interesse há três que se destacam, sendo citadas pela maioria dos especialistas: atratividade do negócio, perfil do empreendedor e inovação. Também mereceram atenção as dimensões modelo de negócios e sobrevivência. De maneira geral, o que se preza ao avaliar um empreendimento é se ele consegue demonstrar que se sustenta ao longo do tempo: no início, o negócio deve ter um diferencial tecnológico que o insira no mercado e, posteriormente, deve ser gerenciado de modo a ser rentável.

Em outra pergunta, procurou-se reunir o que os especialistas têm visto como boas práticas para acompanhar incubadas ou empresas apoiadas pelo fundo. Um ponto que ficou muito claro na discussão com os entrevistados foi o de que a relação entre gestores e geridas é marcada principalmente pelo controle e não pela confiança. Isso porque os gestores têm um compromisso não só com o empreendedor mas também com os provedores de recursos (governo/ investidores). Logo, uma série de práticas vem reafirmar essa postura: reuniões para avaliar o cumprimento de metas, constantes telefonemas/troca de e-mails, relatórios de desempenho financeiro etc. No entanto, uma das especialistas acredita que "esses mecanismos de acompanhamento são interessantes, pois criam um hábito de prestação de contas e isso é bom tanto para a incubadora/fundo de VC quanto para o empreendedor".

A última pergunta dirigida aos membros do grupo Neutro visava identificar como as oportunidades apresentadas pelas incubadas e/ou clientes chegavam às organizações. Para quantificar a frequência com que cada canal era utilizado foi adotada uma escala de 1 a 5, cada extremo correspondendo a, respectivamente, nunca e frequentemente. Essa pergunta foi igualmente dirigida aos membros do grupo Mercado e, por isso, os resultados de ambos os grupos foram consolidados. Analisando esses dados, foi possível identificar algumas tendências:

- Certas incubadoras têm por política só analisar empresas que estejam cadastradas em seus sites, isso justifica a não utilização de outros canais;

- A maioria dos canais teve moda igual a 1 , ou seja, irrelevante;

- A maioria dos canais cuja média é superior a 2 privilegiam a interatividade: p.ex., networking pessoal, congressos/eventos, telefone.

\subsubsection{Mercado}

0 grupo Mercado foi constituído pelos seguintes colaboradores: 
- 1 sócio e 1 gestor regional de um fundo com atuação nacional, que foram entrevistados separadamente;

- 1 gestor de um fundo de venture capital de São Paulo;

- 1 gestora de um fundo de private equity de São Paulo;

- 1 consultora que presta serviços a um fundo de São Paulo.

0 questionário voltado ao grupo Mercado foi montado de forma a atender à exigência de praticidade de preenchimento por parte dos entrevistados. Para isso, o questionário foi baseado no artigo de Elango et al. (1995), o qual serviu de base de comparação (benchmarking) para os dados obtidos com os membros do grupo Mercado.

Dos 4 fundos analisados (A, B, C e D), um é voltado para capital semente (B), dois para venture capital (A e C) e um para private equity (D). Cruzando os perfis dos fundos brasileiros com os dos parceiros de benchmarking, é possível notar algumas semelhanças e diferenças. No campo das similaridades, nota-se que o único fundo que não lidera todos os investimentos de que participa é o fundo com foco em PE, o que se alinha com a tendência norte-americana. Além disso, as taxas mínimas de atratividade exigidas pelos fundos em estágios iniciais ( $A, B$ e $C$ ) são maiores que as daqueles em estágios finais (D).

Já no campo das diferenças, percebe-se que as estruturas brasileiras são um pouco mais enxutas que as norte-americanas, contando com 2 sócios em vez de 3 a 5. Outra discrepância está no tempo médio de acompanhamento de empresas apoiadas pelo fundo por parte dos gestores brasileiros: ele é muito inferior ao praticado pelos gestores norte-americanos, à exceção do fundo D. Por fim, o número de empresas monitoradas por gestor é ligeiramente inferior ao dos fundos norte-americanos, o que explica talvez a estrutura mais enxuta dos fundos brasileiros.

Uma vez analisados os perfis dos fundos A, B, C e $\mathrm{D}$, foram avaliados quatro conjuntos de critérios de investimento: o empreendedor, o produto, o mercado e a oportunidade de investimento. Cada critério foi apresentado sob a forma de uma afirmação (p.ex., "0 empreendedor mobiliza esforços de maneira intensa e constante”). 0 entrevistado deveria julgar a importância de cada critério de acordo com a seguinte escala tipo likert: essencial (ES), muito importante (MU), importante (IM), desejável (DE) e irrelevante (IR).

Como o número de entrevistados foi inferior a 10 , não seria coerente fazer uma análise quantitativa das respostas, por isso a solução adotada foi a seguinte:

- Para cada critério, verificou-se a moda das respostas (nível da escala likert mais citado). Se a moda foi citada por pelo menos três especialistas, então ela foi escolhida como a opinião do grupo. Quando isso não aconteceu, foi adotada a resposta mediana como opinião do grupo;

- Ao mesmo tempo, as respostas obtidas por Elango et al. (1995) foram convertidas da escala numérica para os cinco níveis supracitados (ES, MU, IM, DE e IR).

Dos 14 critérios avaliados, 6 geraram opiniões semelhantes, 5 foram mais valorizados pelos brasileiros e 3 foram mais valorizados pelos norte-americanos. De maneira geral, os fundos norte-americanos, segundo Elango et al. (1995), preocupam-se um pouco mais com a figura do empreendedor e com a exclusividade do produto (patentes/unicidade), enquanto que os fundos brasileiros se atêm mais ao sucesso do negócio dentro do mercado (no que concerne à aceitação de mercado, competição significativa e retorno, bem como se poderá ser desinvestido rapidamente).

Assim como o grupo Neutro, os especialistas do grupo Mercado também foram questionados quanto aos canais mais utilizados para a geração das oportunidades de novas empresas para serem apoiadas pelo fundo. No entanto, para os investidores é interessante saber não só quais canais são mais utilizados, como também em quais deles há maior probabilidade de se encontrar propostas que se tornem investimentos. Nesse sentido, uma pergunta adicional foi criada para o grupo Mercado, inspirada em dados do censo brasileiro de private equity e venture capital elaborado por Carvalho, Ribeiro e Furtado (2006).

Pela análise da tabela percebe-se que a via espontânea é a que gera o menor número de investimentos, tanto em valores absolutos quanto relativos (investimentos/propostas). Já a recomendação e a prospecção geram números absolutos de investimentos realizados muito próximos. 0 que é curioso é que embora o benchmarking seja ter uma taxa de sucesso maior através da prospecção, tanto o fundo B quanto o fundo C têm maiores taxas de sucesso através da recomendação. No entanto, os fundos B e C parecem estar mais propensos à prospecção, pois cada um deles tem um número absoluto de propostas analisadas via prospecção maior do que o de propostas recebidas via recomendação.

Por fim, os entrevistados avaliaram a importância de alguns dos serviços normalmente prestados a empresas apoiadas pelo fundo, valendo-se da escala tipo likert anteriormente apresentada. Dos 12 serviços avaliados pelos fundos brasileiros e norte-americanos, 4 obtiveram importância semelhante, 5 foram destacados pelos fundos norte-americanos e 3 foram destacados pelos fundos brasileiros. De modo geral, os serviços mais prezados pelos norte-americanos são aqueles que envolvem a equipe da empresa apoiada pelo fundo (servir como confidente do empreendedor, recrutar gestores, ajudar a formar e gerir a diretoria), 
o que corrobora a tese de que os norte-americanos se preocupam um pouco mais com os recursos humanos. Já os brasileiros prezam a participação em atividades críticas, como o planejamento estratégico, o planejamento operacional e a avaliação de aquisições da empresa apoiada pelo fundo.

\subsubsection{Empreendedores}

O grupo Empreendedores foi composto por gerentes e/ou fundadores de sete empresas de base tecnológica ligadas a incubadoras. Como todas as empresas analisadas estão ligadas a incubadoras, foi retomada a pergunta que havia sido feita ao grupo Neutro a respeito das motivações dos empreendedores para buscar suporte em incubadoras.

Analisando as respostas dos entrevistados percebemos que os empreendedores procuram as incubadoras por três motivos principais: networking, apoio na captação de recursos e apoio na gestão do negócio - o que é natural para PMEs, pois elas sabem que para crescer precisam criar uma carteira de clientes/fornecedores, ter acesso a recursos financeiros e melhorar seus processos de gestão. Também não é estranho que nenhum empreendedor tenha citado fatores como poder de marca e apoio à internacionalização, mais valorizados em momentos posteriores no ciclo de vida das PMEs.

Dentre as boas práticas de acompanhamento nas incubadoras, os empreendedores ressaltaram:

- A cobrança de resultados por meio de metas;

- A redação de relatórios mensais, muitas vezes apoiados por plataformas eletrônicas;

- As reuniões periódicas de orientação, dando suporte em questões como montagem do plano de negócios, obtenção de patentes, entre outras; $\mathrm{e}$

- A proposição de cursos aos empreendedores.

Cada empreendedor foi levado a fazer uma "autoavaliação" do desempenho de sua empresa através de uma série de perguntas inspiradas no artigo de Chen (2009). Nesse estudo, o autor trata da competência de comercialização tecnológica, isto é, da competência de a empresa utilizar tecnologias ao longo de uma ampla gama de mercados, incorporar grande variedade de tecnologias em seus produtos e levá-los mais rapidamente ao mercado. A lógica proposta por Chen (2009) é que a competência de comercialização tecnológica media as relações entre recursos, capacidades e desempenho de novos negócios.

Nesse sentido, foram apresentadas ao grupo Empreendedores afirmações a respeito do desempenho de seus negócios, de seus recursos organizacionais, de sua capacidade inovadora e de sua competência de comercialização tecnológica. Cada afirmação foi avaliada segundo a seguinte escala de likert: concordo totalmente (CT), concordo em parte (CEP), não concordo nem discordo (NCND), discordo em parte (DEP) e discordo totalmente (DT).

Foi possivel notar que, em geral, os empreendedores acreditam que sua empresa dispõe de bons recursos organizacionais e de uma boa capacidade inovadora. Logo, é natural que elas possuam boa competência de comercialização tecnológica - o que foi, de fato, confirmado pela maioria dos empreendedores quanto à velocidade de comercialização, ao escopo de mercado e à amplitude tecnológica dos produtos das empresas.

No entanto, ao cruzar a opinião dos empreendedores sobre o desempenho e a competência de comercialização tecnológica de sua empresa percebemos que não há uma correlação evidente. De acordo com o modelo proposto por Chen (2009), uma das possíveis fontes de explicação desse fenômeno estaria ligada ao suporte dado pelas incubadoras e fundos de venture capital. 0 autor descobriu essa influência analisando uma amostra de 122 empresas taiwanesas através de delineamentos de experimentos (DOE).

Transpondo a tese de Chen (2009) para este estudo, pôde-se depreender que ela explica apenas parte da diferença de desempenho entre as sete empresas analisadas. Outro fator relevante é a alta confiança dos empreendedores nos recursos de sua empresa, o que faz com que arrisquem-se a não enxergar eventuais pontos de melhoria.

\subsection{Apresentação do caso}

Conforme mencionado na seção introdutória deste trabalho, tanto a síntese da literatura quanto o painel de especialistas forneceram insumos para a análise do CVC da organização apresentada na seção de Método (ver seção 3).

A unidade de análise da organização estudada foi a área de novos negócios (NN) da organização, criada em julho de 2008, com o objetivo principal de alavancar ativos da Organização (como competência técnica, relações comerciais e marca) para ganho de capital por meio de investimentos em empresas emergentes (INSTITUIÇÃO..., 2008, p. 1).

A área de NN da organização, na fase inicial de implementação, estabeleceu um contrato com uma instituição parceira (IP), conforme já mencionado, em parte para mitigar as restrições de tamanho da equipe e em parte para auxiliá-la na tarefa de elaboração de um programa de CVC.

As motivações da busca da IP coincidem com as aquelas apresentadas no painel de especialistas (ver Quadro 4): busca de especialistas na área de inovação, inserção em políticas públicas para inovação (incentivos e Lei do Bem). Dessa forma, a IP foi selecionada pela sua expertise na prestação de serviços de gestão 
da inovação, na gestão de capital empreendedor, no uso de incentivos fiscais e captação de recursos para inovação.

A área de NN, à época da pesquisa, não havia procurado incubadoras, mas via potencial nessa interação, tanto na busca de novas oportunidades de investimentos quanto de parceiros tecnológicos. Não houve menção às questões codesenvolvimento e inovação aberta, nem à redução dos custos de desenvolvimento, aspectos que surgiram no painel de especialistas (ver Quadro 4).

\subsubsection{Atividades de CVC na área de novos negócios}

A NN atua em duas frentes diferentes principais:

- Auxiliando um fundo de investimentos, joint-venture da organização com um banco de investimentos; e

- Selecionando e acompanhando oportunidades de investimento da própria organização, sendo esta frente designada Investimentos Proprietários.

0 que distingue as duas frentes é o tipo de investimento ao qual elas se dedicam. 0 fundo está focado em operações de private equity (PE), ou seja, "investimentos em empresas maduras", geralmente na casa das dezenas de milhões de reais. Já a frente de Investimentos Proprietários está focada em operações de venture capital (VC), ou seja, geralmente na casa dos milhões de reais (CARVALHO; RIBEIRO; FURTADO, 2006). Este trabalho foca-se, portanto, na segunda frente.

A área de NN da organização, por conta de suas restrições de equipe e orçamento, não consegue analisar um volume muito grande de teses de investimento. Assim, ela tem interesse em utilizar os canais certos para encontrar rapidamente as empresas nas quais irá investir. Essa fase, anterior a qualquer triagem de teses, é denominada geração.

Por outro lado, na época em que este trabalho foi iniciado, a área de NN esperava fechar seus primeiros negócios até o final de junho de 2009 e, portanto, passaria a realizar todo o acompanhamento das empresas apoiadas pelo fundo. Como esse processo ainda não havia sido estruturado pela equipe NN, seria um dos grandes desafios que estavam por vir.

Para estruturação de suas atividades, a instituição parceira propôs o Projeto Capital Empreendedor, que contempla duas fases: a primeira, uma fase pontual de análise de oportunidades (2-3 meses) e a segunda, uma fase contínua de gestão de teses e investimentos.

Na primeira fase, de análise de oportunidades, o objetivo foi identificar e avaliar teses de investimento alinhadas aos objetivos da organização.
Uma vez que o formato dos descritivos de oportunidades de investimento foi consolidado, passou-se então à segunda fase do Projeto Capital Empreendedor (gestão de teses e investimentos), que tem sido realizada de forma contínua até o presente momento.

Nessa fase, faz-se uma triagem das oportunidades (pipeline), com base nos fatores qualificadores mencionados anteriormente. As empresas que passam por este pipeline são contatadas e, após diversas reuniões, verifica-se a atratividade de se investir nelas. É nesse momento que começam a atuar o Comitê de Investimento da Organização - corpo diretivo, que se responsabiliza pela decisão de investir ou não em uma empresa - e o Comitê de Investimento da Instituição Parceira - profissionais com ampla experiência na área de investimentos e que atuam de forma consultiva.

Uma vez o investimento autorizado, a empresa que recebe o investimento é acompanhada pelas equipes $\mathrm{NN}$ e IP ao longo de todo o período pelo qual planejou receber investimentos (horizonte de planejamento). Normalmente, considera-se um horizonte de planejamento de 4 a 5 anos. Findo esse período, o investidor pode retirar seu investimento, acrescido do retorno obtido. Essa transação é denominada "desinvestimento" ou "saída de investimento".

Observa-se, portanto, que a área de NN está nas fases iniciais de estruturação do processo de VC apresentadas por Tyebjee e Bruno (1984). Até a conclusão deste trabalho (novembro de 2009), a organização não chegou a atuar nos estágios de gestão de investimentos e saída, pois não havia fechado nenhum investimento em empresa emergente. Por consequência, é incoerente falar no modelo de gestão que a empresa utiliza para acompanhar suas empresas apoiadas pelo fundo de VC, uma vez que ele ainda não está em concepção.

\subsubsection{Critérios para a análise de novos investimentos}

A fim de selecionar as empresas emergentes, foram definidos certos fatores qualificadores:

- Atuação em áreas similares às da organização (foco em Energia e Tecnologias da Informação e Comunicação - TIC);

- Ineditismo mercadológico/comercial (fazer algo diferente ou algo que se faça fora do Brasil e não aqui);

- Tecnologia consolidada ou desenvolvível no curto prazo (time-to-market);

- Perfil dos empreendedores alinhado com a filosofia da organização; e

- Se possível, faturamento anual superior a R\$ 5 milhões. 
Observa-se, portanto, o alinhamento dos setores alvo da área de NN com aqueles apontados pelo painel de especialistas como Energias e TIC. Temas como Biotecnologia e Nanotecnologia foram desconsiderados por falta de alinhamento aos mercados alvo da organização.

Por outro lado, observa-se uma contradição com a afirmação de Zider (1998) de que é um mito considerar que capitalistas investem "em boas pessoas e boas ideias", uma vez que na organização há uma preocupação na escolha de empreendedores alinhados à sua filosofia, sem perder o foco nos setores industriais mais atrativos.

A estratégia de geração adotada pela organização consiste em atacar todo o espectro de fontes de negócios de VC. Por um lado, o contrato com a instituição parceira traz uma ampla gama de oportunidades, pois a IP possui boa capilaridade no território nacional (com vários escritórios regionais). A equipe NN está aberta a recomendações de empresas que the forem feitas e pretende prospectar nichos de mercado em que possa investir.

No que concerne à seleção de empreendimentos inovadores, tanto o diagnóstico da organização quanto a pesquisa bibliográfica evidenciam a dificuldade de se encontrar negócios alinhados aos interesses dos investidores, por isso a literatura de $\mathrm{VC}$ procura entender uma série de questões que seriam responsáveis por essa situação, desde aspectos diretamente ligados às organizações (como seu relacionamento com empreendedores e coinvestidores) até aqueles que exercem influência indireta sobre elas (p.ex., políticas públicas).

Observa-se que nesta fase inicial de estruturação a organização tem alicerçado sua fase de geração basicamente em recomendação da IP, não havendo relatos do uso de prospecção, embora vejam essa atividade como chave, nem de propostas espontâneas de empreendedores ou fundos, outros dispositivos que emergiram do painel de especialistas (ver Tabela 2).

\subsection{Framework proposto}

Confrontou-se a revisão de literatura com o painel de especialistas e com o diagnóstico inicial da organização, identificando lacunas, aspectos divergentes e convergentes. Após discussão com a equipe NN, verificou-se que a proposta mais apropriada para a geração, no contexto da organização, é uma combinação entre apresentação espontânea (com terceirização) e recomendação (sem terceirização). Eis os motivos:

- A geração consome bastante tempo e recursos humanos. Por isso, a organização prefere arcar com os custos de terceirização, a fim de obter mais rapidamente boas oportunidades de investimento. Ao terceirizar a apresentação espontânea, a organização tem acesso a um maior leque de oportunidades já triadas pela empresa contratada, o que lhe permite obter uma maior taxa de sucesso; e

- A recomendação sem terceirização não exige grandes mudanças em termos de verba e equipe na área de NN, sendo uma solução bastante cômoda para a organização, já que ela não precisaria mobilizar recursos para encontrar boas oportunidades, porém é de alcance menor.

Desse modo, chegamos à árvore de decisões sintetizada na Figura 6.

Pensando em como apresentar a solução para o acompanhamento, foi sugerido pela equipe NN a definição, para cada um dos membros do núcleo (empreendedores, gestores e comitês/fóruns de gestão), de seu papel e responsabilidades, além das principais atividades por eles exercidas. Esse formato traça um panorama que permitirá à organização moldar seu processo de gestão das empresas apoiadas pelo fundo com maior flexibilidade. A determinação dos principais papéis e responsabilidades foi pautada nas observações feitas pelo painel de especialistas. A solução é apresentada na Quadro 5.

Tabela 2. Relação investimentos/propostas em função do meio de apresentação.

\begin{tabular}{|c|c|c|c|c|c|}
\hline & Definição & & Censo de PE/VC & Fundo B & Fundo C \\
\hline \multirow{3}{*}{ Espontânea } & \multirow{3}{*}{$\begin{array}{l}0 \text { empreendedor entrou em contato } \\
\text { com o fundo }\end{array}$} & Propostas recebidas & 2.297 & 700 & 55 \\
\hline & & Investimentos realizados & 6 & 3 & 0 \\
\hline & & Investimentos/propostas & $0,26 \%$ & $0,43 \%$ & $0,00 \%$ \\
\hline \multirow{3}{*}{ Recomendação } & \multirow{3}{*}{$\begin{array}{l}\text { A oportunidade foi apresentada ao } \\
\text { fundo por um terceiro }\end{array}$} & Propostas recebidas & 1.301 & 25 & 80 \\
\hline & & Investimentos realizados & 16 & 3 & 2 \\
\hline & & Investimentos/propostas & $1,23 \%$ & $12,00 \%$ & $2,50 \%$ \\
\hline \multirow{3}{*}{ Prospecção } & \multirow{3}{*}{$\begin{array}{l}0 \text { fundo achou a oportunidade por } \\
\text { conta própria }\end{array}$} & Propostas analisadas & 177 & 75 & 125 \\
\hline & & Investimentos realizados & 13 & 3 & 3 \\
\hline & & Investimentos/propostas & $7,34 \%$ & $4,00 \%$ & $2,40 \%$ \\
\hline
\end{tabular}




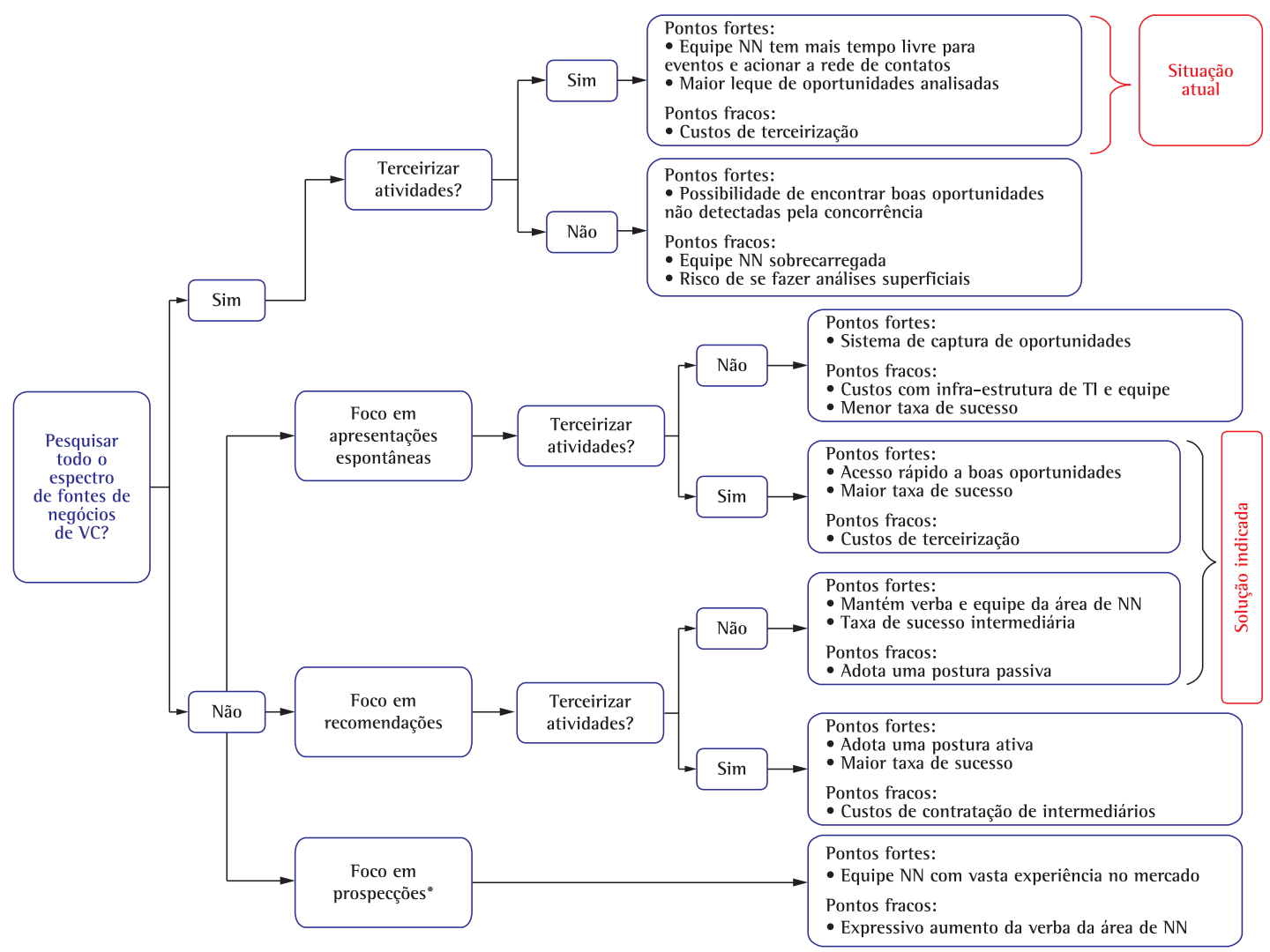

Figura 6. Árvore de decisões para a geração de novas oportunidades de empresas a serem apoiadas pelo fundo. *A organização não cogita terceirizar atividades com foco em prospecções.

Quadro 5. Diretrizes para o acompanhamento de empresas apoiadas pelo fundo.

\begin{tabular}{|c|c|c|c|}
\hline Atores & Principais papéis e responsabilidades & Principais atividades & Frequência sugerida \\
\hline \multirow{7}{*}{ Empreendedor } & \multirow{2}{*}{$\begin{array}{l}\text { Aprender a conduzir seu negócio de } \\
\text { forma autônoma }\end{array}$} & Emissão de relatórios & Mensal \\
\hline & & Cursos & Semestral \\
\hline & \multirow{2}{*}{ Desenvolver competências } & Suporte de consultoria especializada & Variável \\
\hline & & Reuniões de orientação & Semanal/quinzenal \\
\hline & \multirow{3}{*}{ Atingir metas } & Reestruturação da empresa & Variável \\
\hline & & Busca de clientes & Semanal/quinzenal \\
\hline & & Negociação com fornecedores & Semanal/quinzenal \\
\hline \multirow{8}{*}{$\begin{array}{l}\text { Gestor do fundo ou da empresa } \\
\text { investidora }\end{array}$} & \multirow{2}{*}{$\begin{array}{l}\text { Ampliar a rede de contatos da } \\
\text { investida }\end{array}$} & \begin{tabular}{|l|}
$\begin{array}{l}\text { Apresentar a investida a potenciais } \\
\text { clientes/fornecedores }\end{array}$ \\
\end{tabular} & Semanal/quinzenal \\
\hline & & $\begin{array}{l}\text { Apresentar a investida a potenciais } \\
\text { prestadores de serviço }\end{array}$ & Semanal/quinzenal \\
\hline & \multirow{2}{*}{$\begin{array}{l}\text { Dar apoio à investida na captação de } \\
\text { recursos }\end{array}$} & Contatar investidores & Mensal \\
\hline & & $\begin{array}{l}\text { Auxiliar o empreendedor a estruturar } \\
\text { seu plano de negócios }\end{array}$ & Mensal \\
\hline & \multirow{3}{*}{ Dar suporte à gestão da investida } & $\begin{array}{l}\text { Acompanhamento contínuo } \\
\text { (telefonemas/trocas de e-mail) }\end{array}$ & Diário \\
\hline & & $\begin{array}{l}\text { Auxiliar o planejamento estratégico } \\
\text { da investida }\end{array}$ & Mensal \\
\hline & & $\begin{array}{l}\text { Auxiliar o planejamento operacional } \\
\text { da investida }\end{array}$ & Semanal/quinzenal \\
\hline & $\begin{array}{l}\text { Trazer o retorno esperado aos } \\
\text { investidores }\end{array}$ & $\begin{array}{l}\text { Apresentação da situação do } \\
\text { portfólio de investidas }\end{array}$ & $\begin{array}{l}\text { Trimestral/ } \\
\text { quadrimestral }\end{array}$ \\
\hline \multirow{2}{*}{ Comitês/Fóruns de gestão } & \multirow{2}{*}{$\begin{array}{l}\text { Coordenar esforços de gestores e } \\
\text { empreendedores }\end{array}$} & Reuniões extraordinárias & Variável \\
\hline & & Eventos/congressos & Semestral/anual \\
\hline
\end{tabular}




\section{Discussões e considerações finais}

Este estudo gerou como resultado duas estruturas teórico-conceituais (frameworks): uma para a geração e outra para o acompanhamento de oportunidades de investimento do tipo venture capital (VC). Ambas suprem lacunas identificadas na organização estudada por meio da análise de duas fases complexas do processo de investimento em empresas emergentes: geração e acompanhamento. A escassez de literatura específica aliada à intenção dos fundos de VC de resguardar informações sobre essas fases estratégicas motivou os autores deste estudo a buscar uma abordagem alternativa.

De fato, esse trabalho ajuda a reduzir uma lacuna evidenciada nos artigos acadêmicos, que geralmente trabalham a partir da perspectiva de um único tipo de ator na indústria de VC (p.ex., empreendedores, gestores, investidores). Assim sendo, o caminho escolhido foi obter uma pluralidade de visões que pudessem abarcar não só o $\mathrm{VC}$, mas também temas atrelados a ele, como inovação e empreendedorismo. Dessa forma, o painel de especialistas, com auxílio do software ATLAS.ti, para análise das entrevistas, ainda pouco utilizado em pesquisas no país, e dos softwares Minitab e Excel para análise das questões fechadas, permitiu integrar a perspectiva de diversos especialistas ligados à temática de VC.

Os questionários dirigidos aos especialistas versaram sobre temas tanto estratégicos quanto operacionais, sendo boa parte das questões lastreada por artigos acadêmicos. 0 diagnóstico obtido trouxe reflexões interessantes a respeito da realidade brasileira, especialmente quando comparada à norte-americana.

Confrontando o estudo de Elango et al. (1995) com as respostas dos especialistas foi possível inferir que o mercado brasileiro valoriza mais a capacidade do negócio se sustentar do que o produto em si ou mesmo o empreendedor. Essa constatação corrobora a visão de Zider (1998, p. 133) de que é um mito considerar que capitalistas de risco investem em boas pessoas e boas idéias.

Os frameworks propostos visaram englobar os pontos de vista dos três grupos entrevistados: Mercado, Empreendedores e Neutro. No entanto, dada a complexidade do tema tratado, os frameworks focam nos estágios iniciais do CVC: geração e acompanhamento. Como sugestão para futuras pesquisas seria interessante analisar quais considerações feitas atualmente continuariam repercutindo nos próximos anos, sendo, portanto, mais críticas, e quais estariam presentes não só em países como Brasil e EUA, mas também em outros polos de desenvolvimento. Além disso, sugere-se investigar outros estágios do CVC.

0 trabalho apresenta uma série de limitações inerentes à abordagem metodológica utilizada. 0 tamanho da amostra do painel de especialistas estratificada por tipo e o estudo do CVC são algumas limitações, bem como a análise de uma única organização, o que restringe os resultados, com limitações para sua generalização em contextos díspares do apresentado.

\section{Referências}

CARVALHO, A. G.; RIBEIRO, L. L.; FURTADO, C. V. A Indústria de Private Equity e Venture Capital: primeiro censo brasileiro. São Paulo: Saraiva, 2006. 135 p.

CARVALHO, M. M. Inovação: estratégias e comunidades de conhecimento. São Paulo: Atlas, 2009. 161 p.

CASTRO, H. G.; CARVALHO, M. M. Gerenciamento do portfólio de projetos (PPM): estudos de caso. Produção, v. 20, n. 3, p. 303-321, 2010. http://dx.doi.org/10.1590/ S0103-65132010005000044

CHEN, C. Technology commercialization, incubator and venture capital, and new venture performance. Journal of Business Research, v. 62, n. 1, p. 93-103, 2009. http:// dx.doi.org/10.1016/j.jbusres.2008.01.003

CHESBROUGH, H. W. Designing Corporate Ventures in the Shadow of Private Venture Capital. California Management Review, v. 42, n. 3, p. 31-49, 2000. http:// dx.doi.org/10.2307/41166041

CHESBROUGH, H. W. The era of open innovation. MIT Sloan Management Review, v. 44, n. 3, p. 35-41, 2003.

CHESBROUGH, H. W.; CROWTHER, A. K. Beyond high tech: early adopters of open innovation in other industries. $R \& D$ Management, v. 36, n. 3, p. 229-236, 2006. http:// dx.doi.org/10.1111/j.1467-9310.2006.00428.x

COOPER, R. G.; EDGETT, S. J.; KLEINSCHMIDT, E. J. Optimizing the Stage-Gate ${ }^{\circledR}$ process: what best practice companies are doing. Research-Technology Management, v. 45, n. 5, p. 21-27, 2002.

CRIATEC. Desmistificando o capital de risco. Rio de Janeiro: Criatec, 2009. $34 \mathrm{p}$.

ELANGO, B. et al. How venture capital firms differ? Journal of Business Venturing, v. 10, n. 2, p. 157-179, 1995. http:// dx.doi.org/10.1016/0883-9026(94)00019-Q

FUNDAÇÃO NACIONAL DA QUALIDADE - FNQ. Relatório de Gestão - Prêmio Nacional da Qualidade. São Paulo: FNQ, 2007. $88 \mathrm{p}$.

GARCEZ, M. P.; ANSELMO, J. L. O Panorama Brasileiro do Capital de Risco: Características, Evolução e Perspectivas. ln: SEMINÁRIO LATINO-IBEROAMERICANO DE GESTIÓN TECNOLÓGICA, 11., 2005, Salvador. Anais... Salvador, 2005.

INSTITUIÇÃO PARCEIRA. Apresentação do Projeto Capital Empreendedor. Campinas: Instituição Parceira, 2008.

JONG, J. P. J. et al. Open innovation in SMEs: trends, motives and management challenges. $\mathrm{ln}$ : ANNUAL MEETING OF THE EUROPEAN ACADEMY OF MANAGEMENT - EURAM, 2007, Paris. Proceedings... Paris, 2007. 
KOEN, P. A. et al. Fuzzy Front End: Effective Methods, Tools and Techniques. In: BELLIVEAU, P.; GRIFFIN, A.; SOMERMEYER, S. The PDMA Toolbook for new product development. New York: John Wiley \& Sons, 2002.

KHURANA, A.; ROSENTHAL, S. R. Towards holistic "front ends" in new product development. Journal of Product Innovation Management, v. 15, p. 57-74, 1998. http:// dx.doi.org/10.1016/S0737-6782(97)00066-0

KIM, J.; WILEMON, D. Focusing the fuzzy front-end in new product development. $R \& D$ Management, v. 32, n. 4 , p. 269-279, 2002. http://dx.doi.org/10.1111/14679310.00259

LATIN AMERICA VENTURE CAPITAL ASSOCIATION - LAVCA. Guia para Term Sheets de Venture Capital e Private Equity. New York: LAVCA, 2008.

LEVY, R. R. Inovação Aberta e Financiamento de Projetos de Inovação. São Paulo: Allagi, 2009.

LOPES, A. P. V. B. V.; CARVALHO, M. M. Evolucão da literatura de inovação em relações de cooperação: um estudo bibliométrico num período de vinte anos. Gestão \& Produção, v. 19, n. 1, p. 203-217, 2012. http://dx.doi. org/10.1590/S0104-530X2012000100014

MORA JUNIOR, C. H. Fatores que influenciam a descontinuidade de programas Seis Sigma: um estudo comparativo de casos. 2009. 227 f. Dissertação de mestrado (Administração)-Universidade Nove de Julho, São Paulo, 2009.

NAKAGAWA, M. Venture Capital e outras fontes de recursos para empreendedores. São Paulo: Fundação Vanzolini, 2009.

NEUENDORF, K. A. The Content Analysis Guidebook. Thousand Oaks: Sage Publications, 2002. 308 p.

PAVANI, C. O capital de risco no Brasil: conceito, evolução, perspectivas. Rio de Janeiro: E-papers, 2003. 98 p.
PRIETO, V. C.; CARVAlHO, M. M. Strategic Alignment and Performance: Brazilian companies in the Medical Diagnostic Sector. The Service Industries Journal, v. 31 n. 13, p. 1405-1427, 2011. http://dx.doi. org/10.1080/02642060903576050

PRIETO, V. C.; CARVALHO, M. M.; FISCHMANN, A. A. Análise comparativa de modelos de alinhamento estratégico. Produção, v. 19, n. 2, p. 317-331, 2009. http://dx.doi. org/10.1590/S0103-65132009000200008

SMITH, P. G.; REINERTSEN, D. G. Shortening the product development cycle. Research-Technology Management, v. 35, n. 3, p. 44-49, 1992.

STEIER, L.; GREENWOOD, R. Venture capitalist relationships in the deal structuring and post-investment stages of new firm creation. Journal of Management Studies, v. 32, n. 3, p. 337-357, 1995. http://dx.doi. org/10.1111/j.1467-6486.1995.tb00779.x

THIOlleNT, M. Metodologia da Pesquisa-Ação. 13. ed. São Paulo: Cortez, 2004. (Coleção: temas básicos da pesquisa-ação).

TYEBJEE, T. T.; BRUNO, A. V. A model of venture capitalist investment activity. Management Science, v. 30, n. 9, p. 1051-1056, 1984. http://dx.doi.org/10.1287/ mnsc.30.9.1051

ZIDER, B. How venture capital works. Harvard Business Review, v. 76, n. 6, p. 131-139, 1998.

\section{Agradecimentos}

Agradecemos aos avaliadores do trabalho, que muito contribuíram para a melhoria do artigo com seus comentários e sugestões. Agradecemos também à CAPES e ao CNPq, pelo suporte ao projeto de pesquisa.

\title{
Corporate Venture Capital: originating and monitoring investment opportunities in innovative companies
}

\begin{abstract}
This study aims to understand the use of corporate venture capital structures (CVCs), identifying the motivations and difficulties in the implementation process, with focus on the generation and monitoring of investment opportunities. The methodological approach was based on a literature review, followed by an exploratory study performed in a service firm, especially in the new business unit dedicated to CVCs. Finally, we used a panel of specialists of the VC, composed of three groups of experts: Market, Entrepreneurs, and Neutral (academics, consultants, and managers of innovation incubators). The analysis of the interviews was performed using the software ATLAS.ti and content analysis, generating an interesting panel about the Venture Capital practices, which may lead not only to the organization studied, but also to those involved in the venture capital industry innovation and entrepreneurship. The study shows the importance of the alignment between the investment options and organization's target markets, as well as the alignment between the entrepreneur and the organization's philosophy. Differences in perception between the actors of the panel of specialists were identified. Finally, the importance of intermediaries as a bridge between innovative companies and CVC was highlighted.
\end{abstract}

\section{Keywords}

Venture capital. Corporate venture capital. Innovation. Entrepreneurship. 